По результатам интерпретации данных ГИС пористость выделенных в разрезе коллекторов при средневзвешенном значении 0,113 д. ед. для месторождения в целом, изменяется для отдельных пластов от 0,069 до 0,163 д. ед. Для блоков I, II, III средневзвешенное значение пористости составляет $0,134,0,125$ и 0,139 д. ед., соответственно.

Коэффициент нефтенасыщенности изменяется от 0,461 до 0,815 д. ед. по отдельным пластам. Коэффициенты средневзвешенной нефтенасыщенности по блокам составляют 0,788 (блок I), 0,712 (блок II) и 0,728 д. ед. (блок III).

Коэффициент проницаемости в скважинах 1 , 20, 58, обеспечивших максимальные дебиты, достигает 58,7, 23,5 и 22,1 $10^{-15} \mathrm{M}^{2}$, соответственно.

Из специальных методов ГИС для выявления интервалов с подвижной нефтью в потенциально продуктивных коллекторах рекомендуется проведение исследований индикаторного метода по радону (ИМР).

Таким образом, разработана надежная методическая основа определения коллекторских свойств исследуемых пластов по материалам комплекса ГИС с использованием данных месторождений - аналогов. Получены обоснованные критерии определения эффективных толщин, коэффициентов пористости, глинистости, нефтенасыщенности продуктивных коллекторов ардатовского горизонта Сплавнухинского месторождения.

\section{Библиографический список}

1. Альбом палеток и номограмм для интерпретации промыслово-геофизических данных. М., 1984. 200 с.

2. Латышева М.Г. Практическое руководство по интерпретации диаграмм геофизических методов исследования скважин. М., 1981. 182 с.

3. Мичурин Г.В. Разделение пластов на коллекторы, возможные коллекторы и неколлекторы по данным ГИС // Недра Поволжья и Прикаспия. 2003. Вып. 34. С. 69-74.

4. Элланский М.M. Петрофизические основы комплексной интерпретации данных геофизических исследований скважин: Метод. пособие. М., 2001.

УДК. 552.53:553.632

\title{
ОТРАЖЕНИЕ В ПЕТРОМАГНЕТИЗМЕ ЗАКОНОМЕРНОСТЕЙ РАСПРЕДЕЛЕНИЯ НЕРАСТВОРИМОГО ОСТАТКА ПО РАЗРЕЗУ СИЛЬВИНИТОВОГО ПЛАСТА ГРЕМЯЧИНСКОГО МЕСТОРОЖДЕНИЯ
}

\section{Г.А. Московский, А.Ю. Гужиков ${ }^{1}$, М.В. Решетников ${ }^{2}$, А.С. Сорокин ${ }^{1}$, С.А. Свидзинский ${ }^{3}$}

Саратовский государственный университет, кафедра петрографии и минералогии

E-mail: MoskovskyGA@info.sgu.ru

${ }^{1}$ кафедра динамической геологии и полезных ископаемых

E-mail: GuzhikovAY@info.sgu.ru

${ }^{2}$ кафедра геоэкологии

E-mail: rmv85@list.ru

ЗОАО «ЕвроХим-ВолгаКалий»

E-mail: lavanda741@yandex.ru

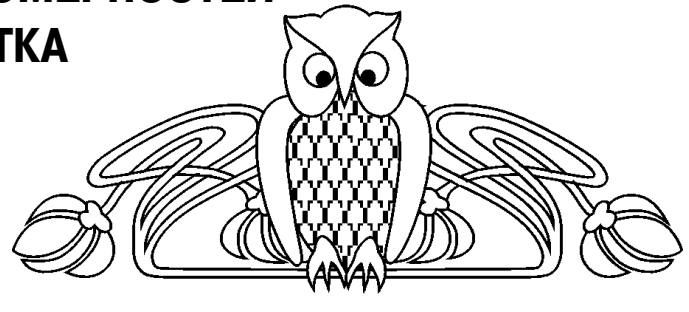

Petromagnetic Effect of an unsoluble residue distribution in the sylvinite Layer Section of the Gremyachinskoe Deposit

\section{G.A. Moskovskiy, A.Yu. Guzhikov, M.V. Reshetnikov, A.S. Sorokin, S.A. Svidzinskiy}

The article presents results of the detailed petromagnetic analysis of the core samples of the potassium salts of the Kungurian potassium salt complex in the Gremyachinskoe deposit (Volgograd region), which allowed for obtaining additional information on the stratigraphic rhythmicity and for substantiating the correlation levels. The connection between magnetic susceptibility variations and changes in the unsoluble residue content over sylvinite layer section has been identified and used as a basis for the development of a new express petromagnetic method of the sylvinite quality evaluation. This method involves no microscopic studies of the thin sections and eliminates the need for the prolonged unsoluble residue extraction through salt dissolving.

Key words: petromagnesism, magnetic susceptibility, unsoluble residue, stratigraphic rhythmicity, correlation levels.

Гремячинское месторождение сильвинитов располагается на юге Приволжской моноклинали, к северо-востоку от Северо-Котельниковского надвига. Сильвиниты месторождения связыва- 
ются с погожской ритмопачкой раннепермских отложений Приволжской моноклинали [1]. Значительное содержание нерастворимой примеси, прежде всего, ангидрита в сильвинитах Гремячинского месторождения определяет необходимость установления закономерностей его распределения в породах продуктивного интервала.

Для решения этой задачи мы использовали принципиально новый прием, заключающийся в использовании петромагнитных характеристик сильвинитов. Возможность такого подхода определялась принятой нами моделью формирования примеси ангидрита в сильвинитах в основном за счет поступления в бассейн как терригенного компонента, сопровождаемого пелитоморфными компонентами, в том числе и гумусовой составляющей, содержащих какое-то количество тонкодисперсных ферромагнитных минералов. Модель основана на наличии значимой зависимости магнитных характеристик породы от объема, заключенного в ней терригенного материала.

Методика исследований заключалась в выпиливании из каждого образца керна сильвинитов 2-5 препаратов стандартного размера кубической формы, которые характеризуют все особенности их состава. В дальнейшем для каждого образца определялись петромагнитные характеристики, они взвешивались, подвергались растворению. Полученные нерастворимые остатки также взвешивались, и проводился их иммерсионный анализ.

На первой стадии были исследованы 88 образцов из фрагментарно отобранных образцов керна скважин 15, 22, 29, 30, 28-1. Измерена магнитная восприимчивость (К) всех образцов, а по скв. 15, кроме того, получены данные о естественной остаточной намагниченности $\left(J_{n}\right)$, остаточной намагниченности насыщения $\left(J_{r s}\right)$ и остаточной коэрцитивной силе $\left(H_{c r}\right)$ (рис. 1). Измерения магнитной восприимчивости и намагниченности проводились на каппабридже MFK1-FB и спин-магнитометре JR-6.

Несмотря на исключительно слабую магнитность изученных образцов солей (от $-1,3$ до $3,5 \cdot 10^{-5}$ ед. СИ), значения петромагнитных параметров обнаруживают значимые вариации по разрезу и могут быть использованы для дополнительного расчленения калиеносного пласта и рас-

$$
\text { К } 10^{-5} \text { ед. СИ· }
$$
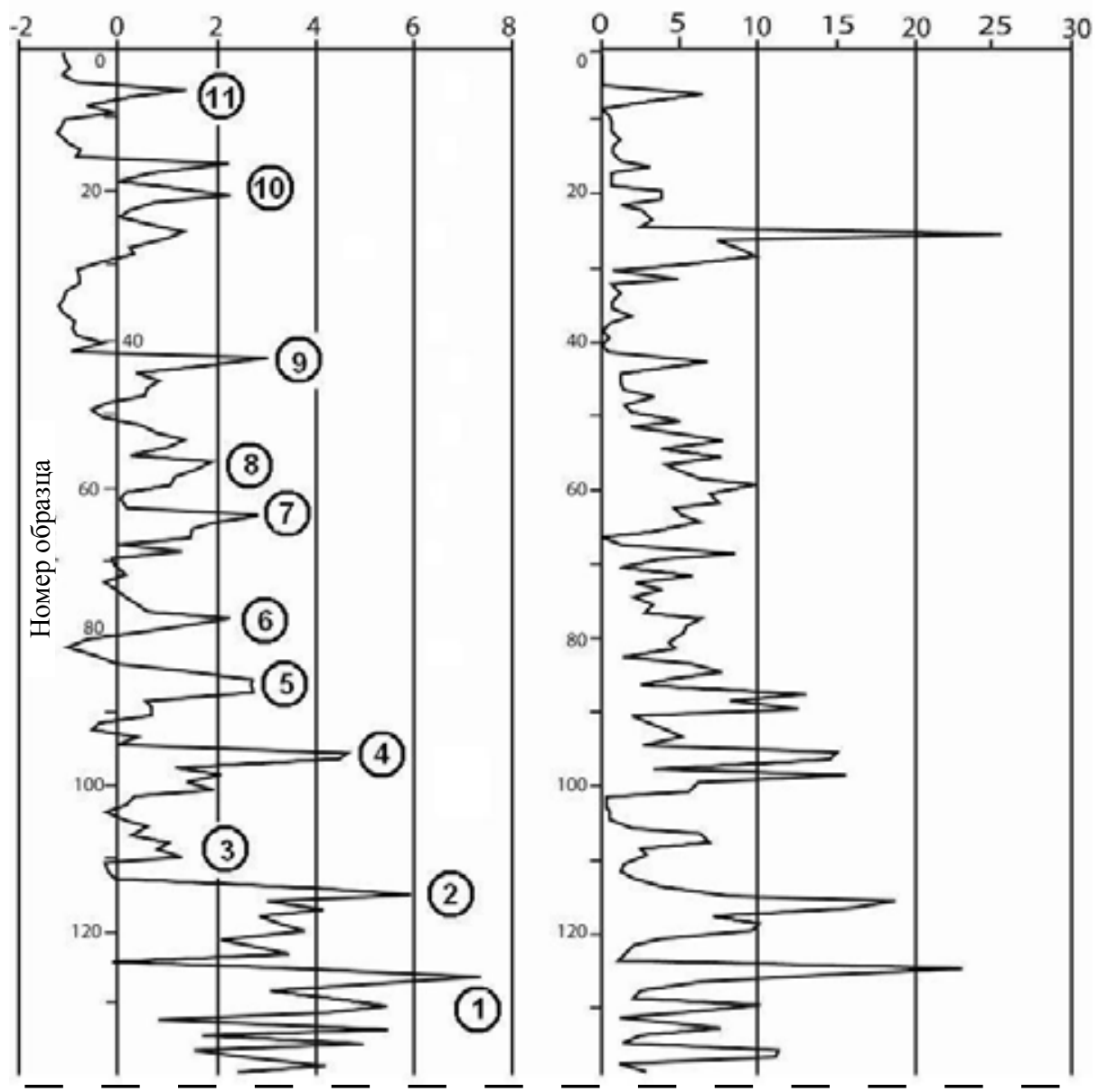

Рис. 1. Петромагнитные характеристики сильвинитовой толщи Гремячинского месторождения калийных солей (скважины $28,15,29,22,30$ ) 
пределения скоплений терригенного материала. Остаточная коэрцитивная сила, величина которой зависит от вида ферромагнетика, может быть использована для выявления образцов с повышенными содержаниями гидроокислов железа. Породы с глубин 1146-1148 м в скв. 15, например, характеризуются повышенными значениями $H_{c r} 440-570$ Э (на фоне 100-250 Э), что указывает на присутствие в них наиболее значительного количества $\mathrm{FeOOH} \cdot \mathrm{nH}_{2} \mathrm{O}$ (см. рис. 1). Графики $K, J_{n}, J_{r s}$ практически идентичны (в скв. 15 коэффициенты парных корреляций между ними близки к 1), и при последующих исследованиях мы ограничились только наиболее экспрессной из них характеристикой - магнитной восприимчивостью К (каппа).

Отрицательные значения К (до $-1,3 \cdot 10^{-5}$ ед. СИ) связаны с наиболее чистыми разностями сильвинита, перистого галита и выдержанным по составу и толщинам ангидритом (см. рис. 1), т.е. с породами, образовавшимися при седиментации в солеродном бассейне. Положительные величины К (до 3,5·10-5 ед. СИ), напротив, отражают наличие терригенных примесей, поскольку соли являются природными диамагнетиками, а терригенные частицы - пара- или ферромагнетиками [2]. Справедливость этого утверждения подтверждена результатами работ по выделению нерастворимого остатка (приведено далее) и изучения состава пород в шлифах. Образцы с диамагнитным эф- фектом практически не содержат нерастворимого остатка, а образцы с положительной К, напротив, характеризовались максимальным количеством терригенных примесей и сульфатов (см. рис. 1).

В дальнейшем исследованию были подвергнуты 188 образцов из 20 штуфов керна скв. 17 (ствол 3) от подошвы до середины калиеносного горизонта. Результаты определения магнитной восприимчивости и нерастворимого остатка в этом массиве образцов отображены на рис. 2 .

Анализ изменений значений магнитной восприимчивости и содержаний нерастворимого остатка по разрезу обнаруживает следующие закономерности.

Общей тенденцией в изменениях величин магнитной восприимчивости по разрезу является периодическая смена аномально высоких (для солей) значений магнитной восприимчивости (от 1,4 до $7,3 \cdot 10^{-5}$ ед. СИ) низкими (отрицательными), типичными для них как диамагнетиков (от $-1,2$ до $0 \cdot 10^{-5}$ ед. СИ), происходящая на фоне тренда к снижению значений К вверх по разрезу.

Сравнение графика $\mathrm{K}$ с литологической колонкой (рис. 3) показывает приуроченность «аномальных пиков» магнитной восприимчивости к интервалам, в которых установлены высокие содержания терригенных компонентов (см. рис. 3), а минимумы петромагнитного параметра связаны с относительно чистыми разностями сильвинитов и галититами (каменной солью).

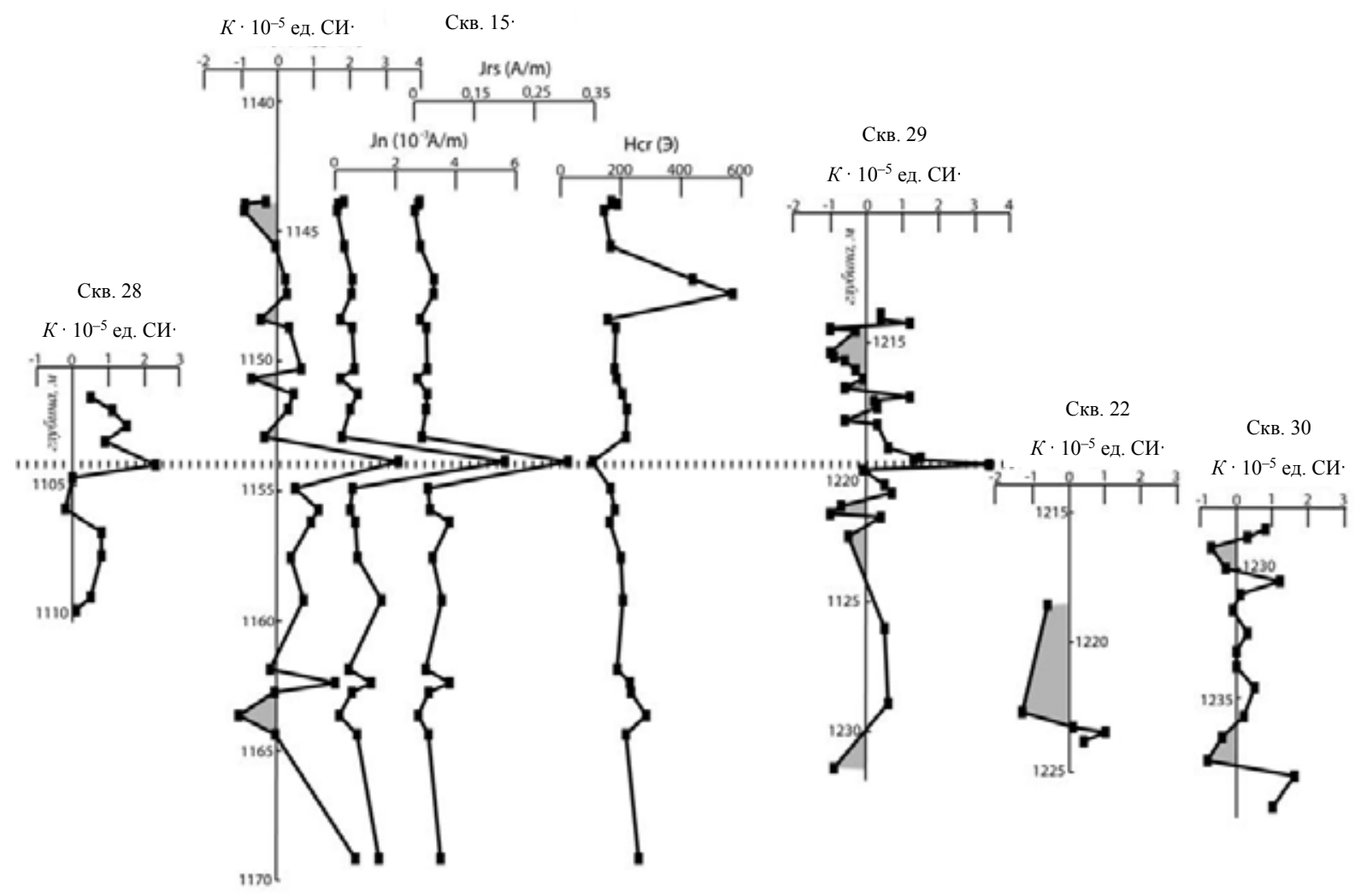

Рис. 2. Графики значений магнитной восприимчивости (К) и содержания нерастворимого остатка (НО) (скв. 17 ствол 3 ) 

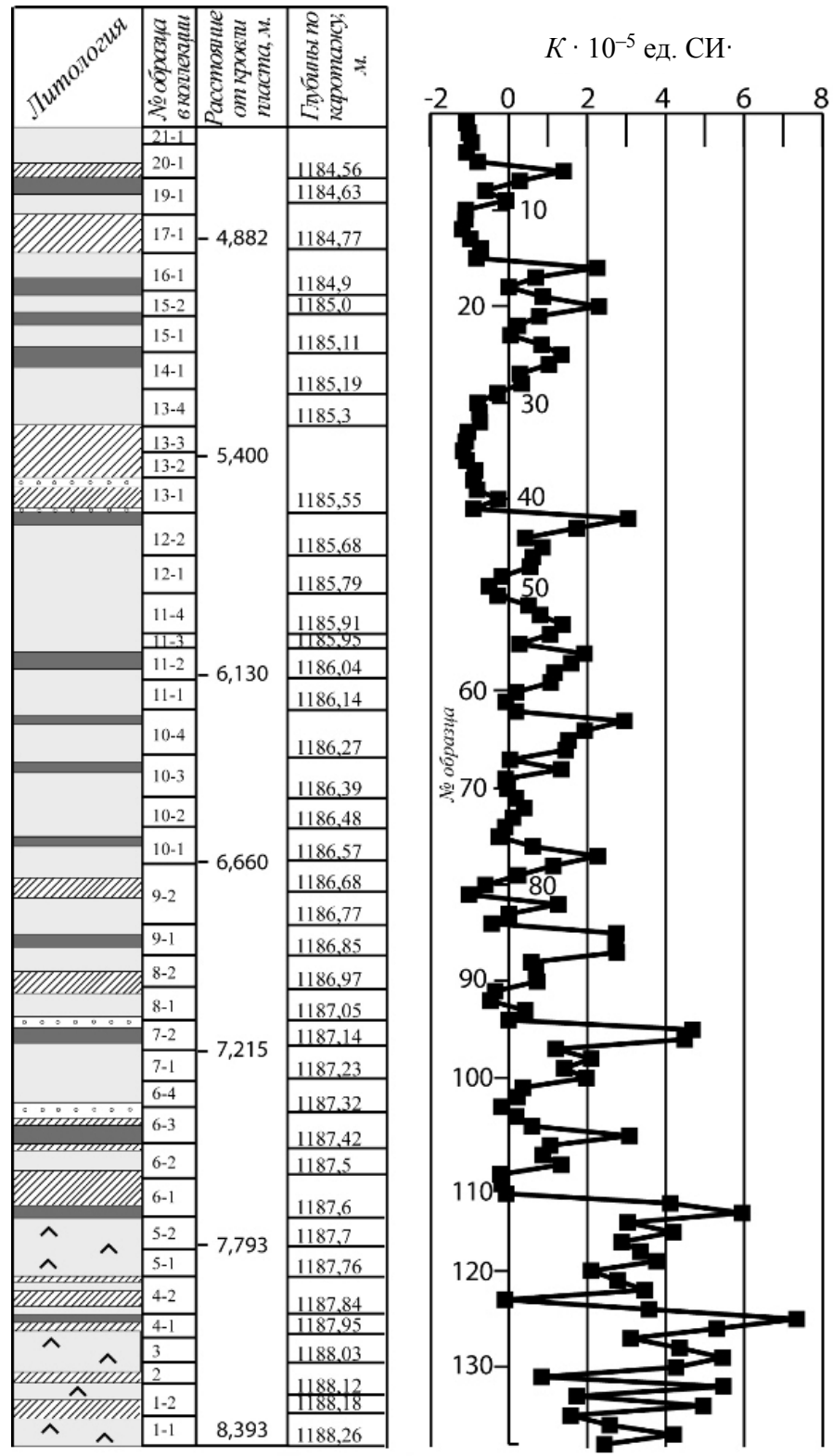

Условные обозначения
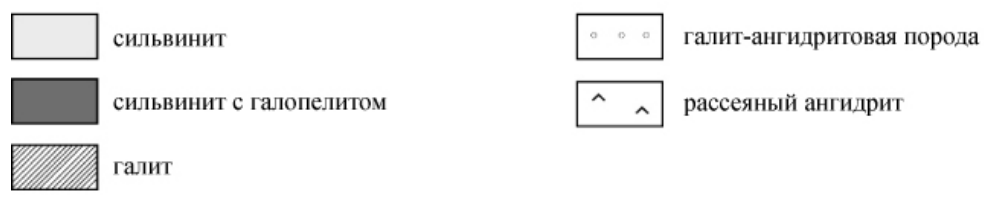

Рис. 3. Петромагнитный разрез скв. 17 (ствол 3)

Тренд к уменьшению величин магнитной восприимчивости вверх по разрезу отражает снижение роли нерастворимых компонентов в продуктивном пласте от его подошвы к кровле. Аналогичный тренд магнитной восприимчивости - уменьшение значений к кровле калиеносного пласта зафиксирован и в скв. 15 с фрагментарным отбором керна, т.е. эта тенденция является общей закономерностью для всего разреза продуктивного пласта.
Величины магнитной восприимчивости тесно зависят от концентраций нерастворимого остатка: коэффициент линейной корреляции между этими параметрами равен 0,49 , что намного превышает его критическое значение $(0,22)$ на уровне значимости $p=0,01$, при объеме выборки (количестве образцов) равном 132. Наличие подобной взаимосвязи предопределяет возможность определения содержаний нерастворимого осадка (HO) по значениям петромагнитных характери- 
стик, не прибегая к длительной и трудоемкой процедуре выделения НО.

Пересчет значений К по отношению к процентному содержанию нерастворимого осадка проводился нами по формуле

$$
\begin{gathered}
\mathrm{HO}=0,0021 \times \mathrm{K}^{6}-0,0324 \cdot \mathrm{K}^{5}+0,1756 \cdot \mathrm{K}^{4}- \\
-0,3726 \times \mathrm{K}^{3}-0,0615 \times \mathrm{K}^{2}+2,4381 \times \mathrm{K}+3,1143,(1)
\end{gathered}
$$

которая представляет собой уравнение полиноминальной кривой, аппроксимирующей содержания HO от K.

Разумеется, показатели НО, рассчитанные по формуле (1) для каждого образца, во многих случаях весьма далеки от реального содержания нерастворимого остатка в породе. Но полученные таким образом величины НО, осредненные для любых интервалов пласта мощностью 2,5 м, весьма удовлетворительно совпадают со значениями истинного среднего содержания нерастворимого осадка в этом интервале (в пределах погрешности $\pm 10 \%$ ) (таблица). С увеличением мощности пласта точность определения процентных концентраций нерастворимого остатка возрастает (см. таблицу).

Зависимость погрешности определения $\mathrm{HO}$ от мощности интервала

\begin{tabular}{|c|c|}
\hline $\begin{array}{c}\text { Мощность интер- } \\
\text { вала, м }\end{array}$ & $\begin{array}{c}\text { Погрешность опре- } \\
\text { деления НО, \% }\end{array}$ \\
\hline 0,25 & 118 \\
\hline 0,5 & 56 \\
\hline 0,75 & 22 \\
\hline 1 & 20 \\
\hline 1,25 & 17 \\
\hline 1,5 & 13 \\
\hline 1,75 & 15 \\
\hline 2 & 12 \\
\hline 2,25 & 12 \\
\hline 2,5 & 12 \\
\hline 2,75 & 8 \\
\hline 3 & 5 \\
\hline 3,25 & 1 \\
\hline
\end{tabular}

Полученные результаты позволяют рекомендовать разработанную нами петромагнитную методику к внедрению в производство для оценки качества сильвинитов и особенностей строения всего продуктивного интервала месторождения. Главным достоинством предлагаемой методики является ее экспрессность: для измерения магнитной восприимчивости одного образца необходимы доли минуты, в то время как процедура извлечения нерастворимого осадка занимает недели и требует предварительного и последующего высокоточного взвешивания образцов.
Основные интервалы с аномально высокими содержаниями терригенных компонентов в продуктивном горизонте месторождения

Вариации магнитной восприимчивости и содержания нерастворимого остатка по разрезу нижней части сильвинитового пласта скв. 17-3 носят ритмичный характер, что позволяет выделить 11 литолого-магнитных интервалов (ЛМИ) (см. рис. 2).

ЛМИ-1 (глубина от 1187,86 до 1188,26 м), располагающийся в подошве сильвинитового пласта, характеризуется высоким содержанием сгустков ангидрита, прослоев ангидритпелитового материала, очень высокой (для данного типа пород) магнитной восприимчивостью (до $7,34 \cdot 10^{-5}$ ед. СИ) и значительными колебаниями в количестве нерастворимого остатка - от 1,22 до $13,84 \%$. Значительный разброс величин характерен и для магнитной восприимчивости при сохранении относительно высоких ее значений для всего интервала. Резкие колебания значений К и содержания нерастворимого осадка адекватно отражают неоднородности строения сильвинитового пласта. Верхнюю границу ЛМИ-1 следует, видимо, проводить по уровню обр. 4-2-Б в слое «перистого» галита, в котором магнитная восприимчивость имеет практически нулевое значение $\left(-0,0091 \cdot 10^{-5}\right.$ ед. СИ). Здесь же отмечается резкий спад содержания нерастворимого остатка с 23,08 до 1,25\%. Подобный слой «перистого» галита встречается и ниже, в обр. 2, но в отличие от упомянутого выше обр. 4-2, он содержит существенную примесь галопелита.

ЛМИ-2 (глубина 1187,5-1187,76 м) характеризуется магнитной восприимчивостью от 2,1 до $5,95 \cdot 10^{-5}$ ед. СИ, причем здесь также совершенно четко отражена периодичность в составе продуктивного горизонта. Максимальные значения $\mathrm{K}$ связаны с наличием в породе существенных примесей терригенного материала, минимальные - с чистыми сильвинитами, что подтверждено анализом содержания нерастворимого остатка. Верхней границей интервала можно считать отложение «перистого» галита в образцах 17-3-6-1 и 17-3-6-2 (глубина 1187,6-1187,42 м) с $\mathrm{K}=-0,21 \cdot 10^{-5}$ ед. СИ.

ЛМИ-3 (глубина 1187,4-1187,35 м) отражает незначительное по масштабам увеличение магнитной восприимчивости, связанное с кровлей образца 17-3-6-2 (сильвинит со слойками ангидритпелитового состава, в котором $\mathrm{K}=1,34 \cdot 10^{-}$ 5 ед. СИ, а нерастворимый осадок составляет $2,63 \%)$ и нижней половиной обр. 17-3-6-3 $\left(\mathrm{K}=0,87-1,06 \cdot 10^{-5}\right.$ ед. СИ). «Перистый» галит, присутствующий в этом образце, был, видимо, неудачно отобран вместе с перекрывающим его слойком галопелита. Но в то же время в образцах 6-3В и 6-3Г установлено высокое содержание нерастворимого остатка, связанное, вероятно, с тем, что значительная часть ангидрита здесь имеет хемогенный генезис. Несмотря на это, высокая 
концентрация нерастворимого остатка достаточно четко отражается в повышении магнитной восприимчивости.

ЛМИ-4 (глубина 1187,05-1187,32 м) связан с интервалом от обр. 17-3-7-1 до 17-3-7-2, где значительное содержание галопелита вызывает соответствующее увеличение магнитной восприимчивости (до $4,49-4,68 \cdot 10^{-5}$ ед. СИ в обр. 7-2). Этому уровню соответствуют и высокие значения нерастворимого остатка (до 14,63 и 14,97 \%). Аномальная зона ограничена сверху резким спадом значений магнитной восприимчивости в образцах 17-3-8-1 и 17-3-8-2. Однако отмечаемое здесь уменьшение содержаний нерастворимого остатка происходит при несколько повышенных их средних значениях по сравнению с предыдущими «спадами» их величин.

ЛМИ-5 (глубина 1186,77-1186,85 м) характеризуется высокими значениями $\mathrm{K}$ в образце 17-3-9-1, где существенная примесь галопелита в сильвините вызывает возрастание значений магнитной восприимчивости 4,49$4,68 \cdot 10^{-5}$ ед. СИ. Сверху аномалия ограничена отрицательными значениями магнитной восприимчивости, связанными со слоем «перистого» галита, выделенного в кровле обр. 17-3-9-2 и в части обр. 17-3-9-3.

ЛМИ-6 (глубина 1186,85-1186,53 м) связан со слоем сильвинита с повышенным содержанием ангидрита и галопелита (обр. 10-1). Величина нерастворимого остатка во всем образце 17-3-10-1 составляет 2,21-3,95\%, увеличиваясь до 6,33\%, что сопровождается максимальным значением магнитной восприимчивости $\left(2,28 \cdot 10^{-5}\right.$ ед. СИ) в аномальном интервале.

ЛМИ-7 (глубина 1186,04-1186,27 м) проявлен лишь в обр. 10-4, где повышенные значения магнитной восприимчивости связаны с общей зараженностью сильвинита ангидритом и галопелитом.

ЛМИ-8 (глубина 1186,04-1185,79 м) отражает довольно широкий интервал (образцы от 11-4 до 11-2) повышенного содержания нерастворимого остатка (в том числе и галопелита, который отмечается в составе НО). Повышенный интервал значений магнитной восприимчивости здесь проявлен отчетливо. Абсолютные значения К при этом понижены пропорциально уменьшению процентного содержания нерастворимого остатка по сравнению с ранее отмеченными аномалиями.

ЛМИ-9 (глубина 1185,68-1185,55 м) отчетливо выражен в обр. 17-3-12-2, где максимальное значение К достигает $3,05 \cdot 10^{-5}$ ед. СИ. Интервал представлен оранжево-красным мелкозернистым сильвинитом с обилием тонких слойков ангидрита с каемками гидроокислов железа. В верхней части образца количество примесей увеличивается и заканчивается слоем ангидрит-галопелита.

ЛМИ-10 (глубина 1185,19-1184,77 м) выделяется по группе аномальных значений нерас- творимого остатка и магнитной восприимчивости, связанных с обр. 17-3-14-1, 17-3-15-1 и 17-3-16-1 (рис. 4). Сильвиниты здесь содержат большое количество тонких слойков, сгустков ангидрита, пелитового материала, окрашенного в красный цвет каемками гидроокислов железа.

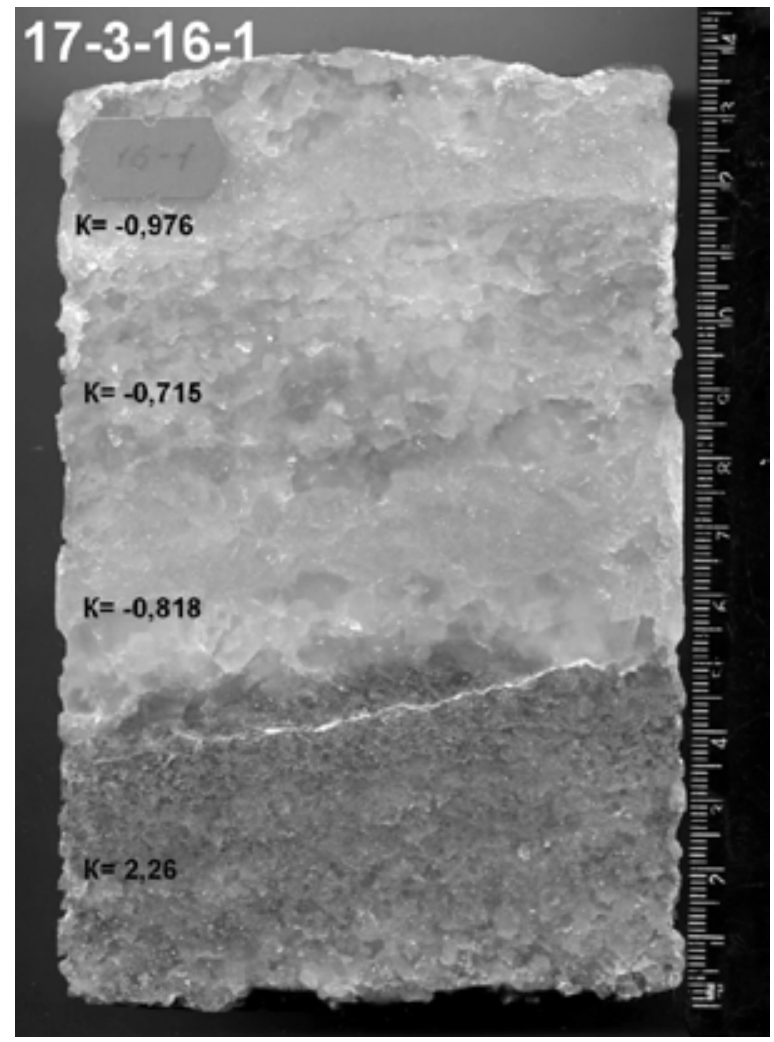

Рис. 4. Образец сильвинита 16-1 из скв. 17 с нанесенными на нем значениями магнитной восприимчивости

$$
\mathrm{K} \cdot 10^{-5} \text { ед. СИ }
$$

ЛМИ-11 (глубина 1184,63-1184,56 м) связан с обр. 19-1, где представлен сильвинит с галопелитом. Аномалии по магнитной восприимчивости и величине нерастворимого остатка в этом интервале полностью совпадают.

\section{Заключение}

Анализ всех результатов, приведенных выше, позволяет сделать следующие выводы.

1. Общей закономерностью изменений величин магнитной восприимчивости и содержания нерастворимого остатка в сильвинитах снижение их значений в направлении кровли сильвинитового пласта.

2. Между величинами магнитной восприимчивости и количеством НО отмечается достаточно устойчивая корреляционная связь, нарушаемая в некоторых случаях за счет увеличения роли компонентов, связанных с садкой из рапы бассейна.

3. Ритмичность, выраженная описанными 
аномалиями, может служить корреляционными признаками для сравнения разрезов продуктивного пласта различных участков месторождения.

4. Столь устойчивая зависимость между значениями магнитной восприимчивости и количеством нерастворимого остатка в сильвините позволяет рекомендовать использование разработанных приемов для экспрессной оценки содержаний нерастворимого остатка в сильвинитах.

\section{Библиографический список}

1. Московский Г.А., Свидзинский С.А., Петрик А.И. Условия формирования галогенных пород района Гремячинского месторождения сильвинитов // Изв. Сарат. ун-та. Новая серия. 2008. Т. 8. Сер. Науки о Земле, вып. 1. С. 75-85.

2. Физические свойства горных пород и полезных ископаемых. Петрофизика: Справочник геофизика. 2-е изд., перераб. и доп. М., 1984. 455 с.

УДК 563.45 (116.3)

\section{ПРОЯВЛЕНИЯ ПОЧКОВАНИЯ СРЕДИ ПОЗДНЕМЕЛОВЫХ СКЕЛЕТНЫХ ГУБОК - ГЕКСАКТИНЕЛЛИД}

\section{Е.М. Первушов}

Саратовский государственный университет, кафедра исторической геологии и палеонтологии

E-mail: pervushovem@mail.ru

Рассмотрение вопросов модульной организации ископаемых скелетных губок - гексактинеллид во многом связано с изучением форм вегетативного размножения этих организмов. Представления о формах размножения рецентных гексактинеллид, а тем более их мезозойских представителей неоднозначны. Приведены примеры ископаемых скелетов губок из верхнемеловых отложений Поволжья, в строении которых выделены морфологически обособленные и закономерно расположенные выросты, интерпретируемые как почки.

Ключевые слова: губки, гексактинеллиды, размножение, почки, поздний мел, тафономия, модульные формы.

\section{Demonstration of Gemmation among Cretaceous Skeletal Sponges - Hexactinellida}

\section{E.M. Pervushov}

The examination of the modular organization in fossil skeletal sponges (Hexactinellida) is mainly related to a study of their vegetative reproduction.

The concepts of the reproductive forms for both Recent and Mesozoic hexactinellids can be ambiguous. Examples of the skeletons of fossil sponges from the Late Cretaceous of the Volga River basin, with morphologically detached and naturally distributed sprouts interpreted as buds, are shown.

Key words: sponges, Hexactinellida, reproduction, buds, upper Cretaceous, taphonomy, modular forms.

\section{Материал и основания для постановки вопроса}

Значительная выборка остатков ископаемых губок, более 10000 экземпляров, из меловых отложений европейской части России и стран ближнего зарубежья дает возможность детально изучить морфологию скелетов этих форм и представить некие производные реконструкции в отношении тенденций в морфогенезе представителей группы и в разработке «иерархических» соотношений. В частности, на протяжении двух десятилетий автор данной статьи то приближается к возмож- но достоверному варианту решения вопроса об уровнях организации скелетных губок - гексактинеллид, то удаляется от него. Асимптотическое приближение к оптимальному представлению, в частности, об одиночных (унитарных) и колониальных формах среди гексактинеллид актуально для систематики представителей группы и кондиционного использования номенклатуры, унификации описаний скелетных форм и выработки целостного видения организации позднемеловых шестилучевых губок.

Описанные примеры регенерации скелетных форм позднемеловых гексактинеллид [1] и известные проявления в формировании дополнительных выростов при искажении или повреждении скелета позволили предположить наличие общей закономерности в расположении активных точек роста в строении губок - гексактинеллид. К предполагаемым зонам расположения точек активного роста были приурочены и участки организма, наиболее способные к регенерации и проявлению вегетативного размножения, в данном случае - почкования. Морфофункциональный анализ скелетных форм гексактинеллид позволяет предположить, что и формирование простейших полиоскулюмных губок («автономий») предопределено особенностями расположения морфологически обособленных зон точек активного роста [2].

Общее количество остатков скелетов губок с почками - в пределах 30 экземпляров, а с разными выростами, неоднозначно интерпретируемым функциональным предназначением, - в пределах 70-100 экземпляров. Из общей выборки ископаемых губок формы с почками и выростами составляют от 0,03 до $0,1 \%$.

Внимание на своеобразные выросты в строении скелета губок было обращено лишь при нахождении их остатков с явно морфологи- 